\title{
New radiodonts with gnathobase-like structures from the Cambrian Chengjiang biota and implications for the systematics of Radiodonta
}

\author{
Cong, P. ${ }^{1,2,3}$, Edgecombe, G.D. ${ }^{2,3}$, Daley, A.C. ${ }^{4}$, Guo, J. ${ }^{5}$, Pates, S. ${ }^{4,6}$, Hou, X. ${ }^{1,3}$ \\ ${ }^{1}$ Yunnan Key Laboratory for Palaeobiology, Yunnan University, Kunming, 650091 China \\ ${ }^{2}$ Department of Earth Sciences, Natural History Museum, Cromwell Road, London, SW7 5BD UK \\ ${ }^{3}$ MEC International Joint Laboratory for Palaeobiology \& Palaeoenvironment, Yunnan University, \\ Kunming, 650091 China \\ ${ }^{4}$ Institute of Earth Sciences, University of Lausanne, Lausanne CH-1015, Switzerland \\ 5 Management Committee of the Chengjiang Fossil Site World Heritage, Chengjiang 652599, China \\ ${ }^{6}$ Department of Zoology, University of Oxford, Oxford OX1 3PS, UK
}

\begin{abstract}
A recent description of paired gnathobase-like structures (GLSs) in the head region of the radiodont Amplectobelua symbrachiata raised the question of whether these appendicular structures are more widely spread within Radiodonta, putative lower stem-group euarthropods. Here we describe a new genus of Radiodonta, Ramskoeldia gen. nov., that also bears GLSs. Its two new species, Ramskoeldia platyacantha sp. nov. and $R$. consimilis sp. nov., are distinguished based on the morphology of their frontal appendages. The presence of three pairs of GLSs associated with reduced segments posterior to the head and the detailed morphological similarities of the GLSs suggest that Ramskoeldia is closely related to Amplectobelua Hou et al., and they are classified together in the revised Family Amplectobeluidae. Other diagnostic characters of this family include the lack of a radially-arranged oral cone, instead sharing mouthparts composed of smooth and tuberculate plates, and a frontal appendage with three podomeres in the shaft and prominent larger endites on podomeres 4 and 8. Due to its lack of GLSs and the different morphology of its mouthparts, membership of Lyrarapax Cong et al., in Amplectobeluidae cannot be confirmed. Appraisal of available evidence indicates that the morphology of the feeding structures, including frontal appendages, the mouth apparatus, and GLSs, serves as a fundamental source of characters in the classification of radiodonts.
\end{abstract}

\section{Introduction:}

Ever since a complete body was first assembled in the 1980s (Whittington \& Briggs 1985), Radiodonta Collins, 1996, a putative part of lower stem-group Euarthropoda (sensu Ortega-Hernández 2016), has been widely perceived as lacking segmental appendages that are comparable to those of euarthropods, apart from a pair of jointed frontal appendages situated anterior to the eyes (e.g. Briggs \& Whittington 1987; Collins 1996). Nonetheless, some authors have identified segmental structures of the trunk as appendicular (Bergström 1986, 1987), and hypotheses have been put forward to 
homologize particular trunk structures of radiodonts with parts of euarthropod appendages, for instance, a possible homology of ventral body flaps of radiodonts and the endopods of euarthropods (Van Roy et al. 2015). The description of additional appendicular structures, so-called gnathobaselike structures (GLSs), associated with reduced segments posterior to the head in the Chengjiang radiodont Amplectobelua symbrachiata Hou et al., 1995 (Cong et al. 2017), invited comparison with feeding structures in euarthropods. Three pairs of these structures are associated with reduced flaps in a one(pair)-to-one(pair) pattern. Together with paired bands of setal blades (Daley et al. 2009) and the inferred limb nature of flaps (Van Roy et al. 2015), the discovery of GLSs in A. symbrachiata added to a framework in which appendicular structures in radiodonts could have evolved before biramous limbs appeared in upper stem-group euarthropods. Such a perspective inspires the search for additional appendicular structures in Radiodonta, especially when describing articulated specimens.

To date, around a dozen genera and over 25 species of radiodonts have been recorded worldwide, spanning a geological time range from the early Cambrian to the Devonian (the latter based on Schinderhannes Kühl et al. 2009; see Legg et al. 2013; Vinther et al. 2014). Most of these species, however, are not known from articulated specimens. At a higher taxonomic level, four families, namely Anomalocarididae Raymond, 1935, Amplectobeluidae Vinther et al., 2014, Hurdiidae Vinther et al., 2014, and the invalidly named 'Cetiocaridae' Vinther et al., 2014 (see Van Roy et al. 2015), have been established based on cladistic analysis of a matrix primarily extracted from the morphology of the frontal appendages (Vinther et al.2014). Owing to the lack of articulated specimens for most species, taxonomy has remained strongly focused on details of the frontal appendages. Nevertheless, it has emerged that other feeding structures such as the mouth apparatus can also serve as a source of diagnostic characters, at least at the generic and specific levels (Daley \& Bergström 2012; Cong et al. 2016). This raises the question whether the GLS feeding structures are also of taxonomic value.

The Cambrian Chengjiang biota in southwest China is well known for its diverse radiodonts, with most of them described based on completely or partially articulated specimens, such as Anomalocaris saron Hou et al., 1995 (Chen et al. 1994), Amplectobelua symbrachiata (Chen et al. 1994; Cong et al. 2017) and two species of Lyrarapax (L. unguispinus and L. trilobus) (Cong et al. 2014, 2016). Here we describe a new genus assigned to Amplectobeluidae, based on two new species from Chengjiang that each include partially articulated specimens. Both new species also bear three pairs of GLSs posterior to a mouth that is composed of smooth and tuberculate plates, a similar arrangement to that of A. symbrachiata (Cong et al. 2017). Diagnostic characters of the family Amplectobeluidae are thus reappraised, and the classification of radiodonts is discussed based on insights from newly documented characters.

\section{Material and method}


The studied materials were collected from mudstones of the Yu'anshan Member, Chiungchussu Formation in eastern Yunnan Province, China, which falls within the Eoredlichia-Wutingaspis Trilobite Zone, Chinese local Nangaoan Stage (equivalent to Cambrian Series 2, Stage 3). YKLP 13315, 13325, 13327, 13331 and 13386 were collected from the Ercaicun section in the Haikou area, Kunming; YKLP 13328, 13329 and 13337 were collected from the Mafang section in the Haikou area, Kunming; CJHMD 00001 and CJHMD 00002 were collected from the Heimadi section, Chengjiang. Detailed stratigraphic information and localities can be found in Hou et al. (2017). When necessary, the specimens were prepared with a steel needle under a Nikon SMZ 800N stereomicroscope. The images were taken with Canon EOS 750D cameras mounted with Canon MPE $65 \mathrm{~mm}(1-5 \times)$ or Canon EF-S $60 \mathrm{~mm}$ macro lenses, and were adjusted for colour and brightness/contrast with Adobe Photoshop CC 2014.2.2. The interpretative drawings were produced with Adobe Illustrator CC 2014.2.2 by tracing the camera lucida drawings and/or the images themselves, with the former being done with a Meiji Techno RZ stereomicroscope. Figures were assembled in Adobe Photoshop CC 2014.2.2.

Terminology: The descriptive terminology mainly follows that of Daley \& Edgecombe (2014) and Cong et al. (2017). The medial dorsal head sclerite is termed the 'central element', following the terminology of Van Roy et al. (2015). The term 'shaft' (Hou et al. 1995) is employed to describe the proximal podomere(s) of the frontal appendage, which normally have more weakly defined articulations than other distal ones; the term 'peduncle' has been employed in some subsequent studies (e.g. Haug et al. 2012). An angle can be normally observed at the dorsal (outer) side of the joint region between the shaft and the distal part of the frontal appendage across a variety of taxa, including Anomalocaris, Hurdia, Amplectobelua and Lyrarapax, indicating that the shaft region of the frontal appendage is a reliable morphologic entity shared within radiodonts.

Institutional abbreviations: CJHMD, Chengjiang Fossil Museum of the Management Committee of the Chengjiang Fossil Site World Heritage, China; Hz, Yunnan Institute of Geological Science, China; NIGPAS, Nanjing Institute of Geology \& Paleontology, Chinese Academy of Sciences, China; YKLP, Yunnan Key Laboratory for Palaeobiology, China.

\section{Systematic palaeontology}


Total group EUARTHROPODA Lankester, 1904

Order RADIODONTA Collins, 1996

Family AMPLECTOBELUIDAE Vinther et al., 2014

Type genus : Amplectobelua Hou et al., 1995.

Diagnosis : Radiodonts with three pairs of gnathobase-like structures associated with reduced transitional segments posterior to the head region; GLSs with at least two rows of stout, curved distal spines set in sockets; distal region of GLS stem bearing numerous pointed scales; mouth composed of smooth and tuberculate plates, not forming a radial oral circlet; shaft of the frontal appendage consisting of three podomeres; frontal appendage with endites decreasing distally except that of podomere 8 , which is larger than podomere 6; endite of podomere 4 larger/stouter than others, varying from slightly larger to hypertrophied; smaller endite present on each distal podomere, forming an asymmetric pair with the normal larger one; P-element small, oval and of similar size to central element of head.

Remarks: Vinther et al. (2014) erected this family based on a cladistic analysis including all thenknown taxa, but using only a phylogenetic definition rather than a character-based diagnosis. The ongoing description of more specimens of the type genus Amplectobelua (e.g. Daley \& Budd 2010; Cong et al. 2017) together with the new genus described herein (see below), allow us to summarize a suite of diagnostic characters of this family for the first time, based mainly on the feeding structures, including details from each of the frontal appendages, mouthparts and GLSs.

Recently, Zeng et al. (2018a) described an isolated tetra-radial oral cone from the Guanshan biota, which resembles the oral cones of Hurdia and Peytoia, and proposed that it might be related to the mouthparts of amplectobeluids. This conjecture is contradicted by the articulated specimens of Amplectobelua symbrachiata, which revealed that the mouthparts of Amplectobelua are not a tetra- or tri-radial oral circlet, but are instead composed of smooth and tuberculate plates arranged in rows (Cong et al. 2017). The new genus Ramskoeldia has a mouth apparatus similar to that of Amplectobelua, indicating that the mouthparts of at least these members of Amplectobeluidae possess similar components, the arrangement of which does not resemble that of Anomalocarididae (as seen in Anomalocaris) or Hurdidae (as seen in Hurdia and Peytoia) (see Daley \& Bergström 2012).

Another genus, Lyrarapax Cong et al., 2014, from the Chengjiang biota has previously been assigned to this family (Cong et al. 2014, 2016) based on an enlarged endite on one proximal podomere that is directed forwards to oppose the tip of the appendage and form a claw. However, given that its 
mouthparts are substantially different from those of Amplectobelua (Cong et al. 2017), and the lack of GLSs in known specimens, membership of Lyrarapax within Amplectobeluidae cannot be confirmed.

Genera included: Amplectobelua Hou et al., 1995 and Ramskoeldia gen. nov. See Discussion below for other potential members of this family.

Occurrence: Stage 3 (Chengjiang, China), Stage 4 (Guanshan, China) and Stage 5 (Burgess Shale, Canada) of Cambrian unnamed Series 2 and Series 3.

Genus RAMSKOELDIA nov. Figures 1-4; 5A, B, D, E

LSID: urn:1sid:zoobank.org:act:5C69AD42-50A2-4969-A9DB-B7E1DDA90EC7

Type species: Ramskoeldia platyacantha sp. nov.

Derivation of name: Named after Dr Lars Ramsköld for his contributions to early research on the Chengjiang biota, and his ingenious idea that some radiodonts bear 'gnathobases' (herein GLSs) (Ramsköld 1995). Gender feminine.

Diagnosis: Amplectobeluid with frontal appendages consisting of 16 podomeres bearing spinose endites, composed of 3 podomeres in the shaft and 13 in the distal articulated region; endites bearing prominent auxiliary spines up to at least podomere 12; endite of podomere 4 larger/stouter than others, but length not exceeding half the length of frontal appendage; three large dorsal (outer) spines on the most distal podomeres.

Remarks: The presence of GLSs in Ramskoeldia, the number in both species counted as three pairs (see description below) and sharing precise details of their structure, indicates that the genus is probably related to Amplectobelua Hou et al., 1995, which is the only other radiodont known to also bear paired GLSs. This relationship is further supported by the components of the mouthparts and the pattern of the endites along the articulated podomeres, such as the enlargement of those on podomeres 4 and 8 (particularly relative to that on podomere 6), as well as the alternation of endite size between the odd- and even-numbered podomeres in both genera.

The endite on podomere 4 of Ramskoeldia is enlarged compared to more distal endites, but it is not hypertrophied like that found in Amplectobelua. Ramskoeldia can also be distinguished from Amplectobelua in having endites with auxiliary spines along the length of the appendage, whereas Amplectobelua has auxiliary spines only on the endite on podomere 4. Both taxa have a shaft of 3 podomeres, but the distal articulated region has 13 podomeres in Ramskoeldia versus 12 in Amplectobelua. GLSs in Ramskoeldia are wider than the height of podomere 5, whereas in 
Amplectobelua symbrachiata the GLSs are two-thirds of the height of podomere 5. The pronounced reduction in the size of the distal spines of the GLSs in Amplectobelua has not been observed in Ramskoeldia, which also has distal spines of the GLS that are more closely spaced than those of Amplectobelua.

Occurrence: Yu'anshan Member, Chiungchussu Formation in eastern Yunnan Province, China, Chinese local Nangaoan stage (equivalent to Cambrian Series 2, Stage 3).

\section{Ramskoeldia platyacantha sp. nov. Figures 1, 2}

LSID: urn:lsid:zoobank.org:act:3AE9E45A-A05D-449E-9490-EC26DF15D543

Derivation of name: Greek platy, wide, plus Greek acanth, spines, alluding to the relatively wide endites (ventral spines) along the podomeres.

Holotype: YKLP 13325, preserving a pair of frontal appendages, six disarticulated GLSs, mouth apparatus, head carapace and fragmentary flaps.

Paratypes: YKLP 13331, YKLP 13337, CJHMD 00001, CJHMD 00002, all of which are isolated frontal appendages.

Diagnosis: Ramskoeldia with short, wide endites on podomeres of distal articulated region of frontal appendage; length of endites not exceeding height of podomere to which they attach, even the largest one on podomere 4 ; endite of shaft podomeres 2 and 3 prominent, resembling those of distal articulated podomeres.

Description: The length of the frontal appendages (exclusive of the shaft) ranges from $2.5 \mathrm{~cm}$ (CJHMD 00002) to c. $15 \mathrm{~cm}$ (YKLP 13337). In some specimens, the shaft and the distal region form an angle at the dorsal (outer) edge of the joint area (Figs 1A-D; 2), with the smallest measured as about $150^{\circ}$ (Fig. $1 \mathrm{~A}-\mathrm{D}$ ), whereas in one specimen the joint edge of these two regions can be straight (Fig. 1G, H). Relatively wide endites are present on the ventral (inner) side of podomeres 4-15, most of which bear two pairs of auxiliary spines (Figs 1A-D, G, H; 2). The endites of several proximal podomeres (podomeres 2 to at least 8 ) are not bilaterally symmetrical, with the auxiliary spines pointing distally (of the frontal appendage) densely arranged and slightly longer than those on the opposite side. This is particularly prominent in large specimens (Fig. 1B, C). Endites on the evennumbered podomeres are significantly larger than those on the following odd-numbered podomeres. In both even- and odd-numbered podomeres, the size of the endites decreases distally, except for that of podomere 8 , which is clearly larger than that of podomere 6 (Figs 1D;2E-H). The endite of 
podomere 4 is stoutest and largest, but like all other endites its length does not exceed the height of the podomere to which it is attached (Figs $1 \mathrm{~A}-\mathrm{D} ; 2 \mathrm{E}-\mathrm{G}$ ). Podomeres $12-15$ bear a dorsal spine, with that of podomere 12 very tiny and those of the other three extremely long. Podomere 16, the most distal one, bears a terminal spine and probably a small dorsal spine (Fig. 2C, D, G, H). Each podomere of the shaft also bears an endite, with that of podomere 2 similar in relative size and morphology to those on the distal podomeres, while the endites of podomeres 1 and 3 are only simple spines (Fig. 2). In large individuals, however, auxiliary spines are present on endite 3 on only the distal-facing side of the frontal appendage; auxiliary spines on the proximal-facing side are absent, making the endites of podomeres 2 and 3 similarly asymmetrical (Fig. 1B, C).

The left frontal appendage of YKLP 13325 possesses an additional spinose endite at the lateral side of each podomere, preserved in high relief due to its pointing nearly vertical to bedding (Fig. 1A, D, F). They are markedly narrower than the ventral (inner) endites, and possibly shorter. On the right frontal appendage of the same specimen, which is in the same orientation as the left one, only the basal attachment of these small endites can be seen on podomeres 6, 7, 9-12 (Fig. 1A, D), indicating that the small endites might only be present on one lateral side of the frontal appendage. If this is the case, it indicates that each podomere of the frontal appendages in $R$. platyacantha has two endites of differing size. In Amplectobelua symbrachiata, the corresponding endite has been noted to arise from the ventrolateral side of the podomeres (Cong et al. 2017), and the size of the two endites of a pair in the same podomere differs (Hou et al. 1995, fig. 15c). We thus tentatively conclude that the paired endites on each podomere of $R$. platyacantha likewise differ in size, similar to those of A. symbrachiata.

In YKLP 13325, six GLSs are preserved. The two in the region to the right of the frontal appendage have their distal spines pointing towards each other, indicating that they might have been paired in life (Fig. 1A, E; Fig. 1D, gls 1). Between these two GLSs are six small tuberculate plates aligned in a row, each of which bears marginal spines (Fig. 1A, E; Fig. 1D, tp). Three dumbbell-shaped plates are also preserved in this region, which is partially overlapped by the GLSs and the tuberculate plates, and are aligned successively along their long axes (Fig. 1A, E, Fig. 1D, sp). The size, shape and position of these three non-tuberculate plates resemble the smooth plates of the mouthparts of Amplectobelua symbrachiata (Cong et al. 2017). In this specimen, there are four other GLSs preserved in a region corresponding to the proximal region of the frontal appendage. They form two pairs, each of which is comprised of two GLSs that are in the same orientation and overlap one another (Fig. 1A; Fig. 1D, gls $2 \& 3$ ). The distal spines of these two rows of GLSs also point towards each other (Fig. 1A, D, F), indicating that they might have been paired in life. However, the available data do not permit these six GLSs to be distinguished into different types, like those in $A$. symbrachiata (Cong et al. 2017). 
The GLSs bear four large, curved distal spines of subequal size, between which are interpolated smaller curved spines that are offset from the large spines. Thus, at least two rows of spines are present. A partial socket is preserved in darker pigmentation at the base of a large distal spine in gls 2 (Fig. 1F, hollow arrow). The distal region of the GLS stem bears numerous small pointed scales.

Other body parts of this species are less well known. In the only (partially) articulated specimen, YKLP 13325, an oval structure is preserved in high-relief between the two frontal appendages (Fig. 1; Fig. 1D, ce). Given its shape and thick marginal line, we interpret it as a head sclerite, specifically a central element. In the same specimen, beyond the distal end of the frontal appendage, there is a fragmentary smooth organic sheet preserved, with a series of parallel linear structures indicative of a body flap (Fig. 1; Fig. 1D, fl). Other fragments of organic material near the GLSs are tentatively interpreted as reduced flaps associated with them (Fig. 1A; Fig. 1D, rf), like those in Amplectobelua symbrachiata (Cong et al. 2017).

Remarks: The presence of consistently short endites on the frontal appendage in Ramskoeldia platyacantha is unique in Radiodonta. The only other specimen described as bearing short endites was attributed to Anomalocaris saron, together with tri-radial mouthparts (characteristic of that genus) and a partial body with flaps and setal blades (NIGPAS 115341, Hou et al. 1995, fig. 6). The mouthparts of $R$. platyacantha (Fig. 1A, D) most probably did not have radial symmetry, rather like those of Amplectobelua symbrachiata, which its disarticulated components resemble (Cong et al. 2017). Thus, the short endites in NIGPAS 115341 are most likely to be the result of incomplete preservation, but no photograph of this specimen has yet been published to allow further examination of details.

Occurrence: Yu'anshan Member, Chiungchussu Formation in eastern Yunnan Province, China, Chinese local Nangaoan stage (Cambrian Series 2, Stage 3).

Ramskoeldia consimilis sp. nov. Figures 3, 4, 5A, B, D, E

p1991 Anomalocaris canadensis; Hou \& Bergström, p. 182, pl. 2 fig. 2, NIGPAS 110827.

p1995 Anomalocaris saron; Hou et al., p. 166, figs 2b, 3a, NIGPAS 110827.

?1999 Anomalocaris saron; Luo et al., pl. 16 fig. 1, Hz-f-4-275.

?p2018bAnomalocaris saron; Zeng et al., fig. 18a-c, p. 23, NIGPAS 162527

LSID: urn:lsid:zoobank.org:act:29AB8613-E80B-4910-B572-87D96C333D2F

Derivation of name: Latin consimilis, very similar, with reference to the morphological similarity of the frontal appendage to that of Anomalocaris saron. 
Holotype: YKLP 13315, preserves a pair of frontal appendages, six disarticulated GLSs, mouth apparatus, head carapace and a set of fragmentary flaps.

Paratypes: YKLP 13327-13330.

Diagnosis: Ramskoeldia with relatively long endites on podomeres of distal articulated region of frontal appendage; length of endite on most articulated podomeres longer than height of podomere to which they attach; endite absent on shaft podomeres 1 and 2.

Description: The frontal appendage is slender, divisible into a shaft and a distal articulated region. An angle ranging from 126 to $148^{\circ}$ can be measured at the outer side of the joint area. Podomeres 4 15 bear spinose endites that have at least one pair of auxiliary spines at the basal part of the main spine (Figs 3A, B, D, E; 4A, B, D-F; 5A, B, D, E). In some specimens, it is clear that the endites arise from the ventrolateral side of the frontal appendage. The size of the endites alternates on even and odd podomeres, with those on even podomeres being larger than that of the odd podomere following it. The endite of podomere 4 is largest and stoutest, with a length that is longer than the height of the podomere to which it is attached, as is also the case for the endites on podomeres $6,8,10$ and 12 . The endite on podomere 4 is prominently asymmetrical, with the main spines slightly curved distally (Figs 3A, B, D, E; 4A, B, D-F; 5A, B, D, E). In addition, there are two auxiliary spines at the distal edge of the main spine, but only a larger one at the opposite edge (Figs 4A, B, D-F; 5A, B, D, E). Podomeres 13-15 have relatively larger dorsal spines, forming a claw-like termination of the frontal appendage together with the terminal spine of podomere 16 ; the dorsal spine of podomere 16 is tiny, only preserved in some specimens (ds of pd 16 in Figs 4E, F; 5D, E). Podomere 3 bears a tiny, simple ventral spine (endite) (Fig 4D, G). In YKKP 13327, an additional cluster of small spines can be observed at the joint corner of endite 4, 5, 8 and 9 (Fig. 4B, C (arrows), F). They might represent the small endite of those podomeres, which forms an asymmetrical endite pair, like in R. platyacantha.

In the holotype YKLP 13315, other body parts are preserved, including the GLSs, the mouth apparatus, a P-element and several flaps. A total of six GLSs can be recognized in an area adjacent to the base of the frontal appendage, within which other mouth parts are also preserved (Fig. 3A, B). We tentatively associate the two GLSs close to the frontal appendage as a pair, primarily based on the fact that their distal spines point to each other (Fig. 3A, B, gls 1). The other four GLSs are located slightly further from the frontal appendage and form two rows. Each row has two GLSs with the same orientations. Because the distal spines of the GLSs of these two rows point to each other, the rows are interpreted as representing two pairs of GLSs (Fig. 3A, C; Fig. 3B, gls 2\& 3). The most distally complete GLSs bear at least four large curved distal spines, and, by comparison with the better known $R$. platyacantha, it is most likely that smaller spines along this edge are part of another row. Small pointed scales are scattered across the distal region of the GLS stem. 
Overlapping the GLSs are smooth plates and tuberculate plates, comparable with those of Ramskoeldia platyacantha and Amplectobelua symbrachiata, arranged in a square (Fig. 3A, C; Fig. $3 \mathrm{~B}, \mathrm{sp}, \mathrm{tp}$ ) and probably reflecting the mouth shape in life. Just above the most proximal part of the paired frontal appendages, an oval sclerite is preserved in high relief, as indicated by a series of concentric wrinkles. One end of this sclerite is slightly more pointed than the other (Fig. 3A; Fig. 3B, pe), indicating that it is asymmetrical along its long axis. This shape is similar to the P-element of A. symbrachiata, rather than its oval central element. Several fragmentary flaps are also preserved in this specimen. Their morphology is typical, having transverse lines across the half-width of the flaps. Several other small pointed structures are tentatively interpreted as the reduced flaps associated with reduced transitional segments (Fig. 3A; Fig. 3B, rf ?).

Remarks: The frontal appendage of Ramskoeldia consimilis was previously included in Anomalocaris saron (Hou et al. 1995). However, given the preservation of GLSs and the lack of a triradial oral cone in Ramskoeldia (e.g. the holotype of R. consimilis, Fig. 3A, B), it is reasonable to distinguish the genus from Anomalocaris, for which GLSs have never been found in or associated with any of the abundant articulated specimens (Chen et al. 1994; Daley \& Edgecombe 2014). Furthermore, the frontal appendage of $R$. consimilis is distinguishable from that of $A$. saron as follows: two podomeres in the shaft of the frontal appendage of $A$. saron (Fig. 5C, F; also see description in Hou et al. 1995) versus three in R. consimilis; more than two pairs of auxiliary spines on the endite of $A$. saron, which normally occur at the mid-length or more distal part of the main spine, versus a maximum of two pairs of auxiliary spines that occur at the basal part of the main spine in R. consimilis; in A. saron, the endite of the most proximal podomere (Fig. 5F, pd 3) in the distal region is the stoutest, but not the longest (Fig. 5C, F), whereas in $R$. consimilis, the endite of the most proximal podomere (podomere 4) is both the stoutest and the longest; and in A. saron, the size of endites does not alternate on the even and odd-numbered podomeres of the distal region, as is seen in $R$. consimilis. The general similarity in the frontal appendages of $R$. consimilis and A. saron, despite their classification in different families, may reflect retention of shared characters of the common ancestor of Amplectobeluidae and Anomalocarididae, which have been resolved as sister groups in recent phylogenetic analyses of Radiodonta (Cong et al. 2014; Vinther et al. 2014; Van Roy et al. 2015).

Occurrence: Yu'anshan Member, Chiungchussu Formation in eastern Yunnan Province, China, Chinese local Nangaoan stage (equivalent to Cambrian Series 2, Stage 3). 


\section{Discussion}

\section{Insights from new observations on feeding structures in the classification of Radiodonta:}

Ever since the first species was documented, the taxonomy of Radiodonta has largely been based on diagnostic characters of frontal appendages, which are the only anatomical features known for a substantial number of species. Frontal appendages are sufficiently differentiated along their proximaldistal and dorsal-ventral axes as to provide many diagnostic characters. An example of the disparity in these appendages would be between those of Tamisiocaris borealis, which bear intricate auxiliary spines for filtering food particles (Daley \& Peel 2010; Vinther et al. 2014) and Amplectobelua symbrachiata, which are specialized as simple but strong spines for holding prey (Chen et al. 1994; Hou et al. 1995; Cong et al. 2017). Such a difference is consistent with the current classification of these two taxa in different families (Vinther et al. 2014). However, the morphology of the frontal appendage can also vary substantially within a single genus. In Anomalocaris, the endites can vary from bearing condensed short, spike-like auxiliary spines in A. briggsi (Nedin 1995; Daley et al. 2013a) to bearing only one pair of short auxiliary spines in A. canadensis (Briggs 1979; Daley \& Edgecombe 2014) to completely absent auxiliary spines in A. pennsylvanica (Briggs 1979). Such variability hinders resolution of the general pattern for the genus itself, let alone at the family level, and there remains the possibility that Anomalocaris might not be monophyletic. The situation becomes more complicated when considering the paired or unpaired nature of the endites, the size of which can be different, as seen here in Ramskoeldia platyacantha (Fig. 1A, D, F). Similar asymmetry in the size of the paired endites can also be found in A. symbrachiata (Hou et al. 1995, fig. 15c). This difference in the size of paired endites indicates that some morphological variations observed in different taxa might cause taxonomic confusion when the frontal appendages have been preserved in different orientations. Despite these factors, some general patterns can still be summarized with regards to the morphology of the frontal appendage, at least in some particular taxa, for example, as here in the Amplectobeluidae, in which shared character states include the same podomere number in the shaft, as well as the size of some particular endites (see diagnosis of the family above).

A radial oral cone has been considered as a universal character of radiodonts, but it is now evident that significantly different mouthparts exist in different taxa, such as the combination of smooth and tuberculate plates in Amplectobelua symbrachiata (Cong et al. 2017) and in Ramskoeldia described here (see description above). Nevertheless, some general patterns of variation in the morphology of the mouthparts can be observed (Fig. 6). In Hurdia and Peytoia, both of which belong to the family Hurdiidae, oral cones are tetra-radial, that is, bearing four large, evenly arranged plates among other radially arranged plates (Daley et al. 2009, 2013b; Daley \& Bergström 2012). In Anomalocaris canadensis (Family Anomalocarididae), the oral cones are tri-radial, with only three large oral plates 
evenly arranged among other plates (Daley \& Edgecombe 2014), which is also the case in the Chengjiang species A. saron (ACD, pers. obs.). Thus it can be tentatively summarized that tri-/tetraradial mouthparts is a potential character to distinguish between the families Anomalocarididae (Anomalocaris) and Hurdiidae (Hurdia, Peytoia). The mouthparts of Amplectobelua (Family Amplectobeluidae) on the other hand differ significantly from both hurdiids and anomalocaridids in lacking radial oral cones, but rather being composed of a set of smooth and tuberculate plates (Cong et al. 2017). It is the congruent signal from this observation as well as the detailed correspondence in the GLSs that underpin Ramskoeldia being allied to Amplectobelua and assigned to Amplectobeluidae. In this sense, the morphology of the mouthparts would be one of the key characters to distinguish the families of Radiodonta.

Gnathobase-like structures of similar morphology are present in Amplectobelua and Ramskoeldia. Other specimens showing plates with teeth have also been assigned to putative radiodonts, although these differ from the morphology of the GLSs of Amplectobelua and Ramskoedia. Specifically, fourcusped teeth have been attributed to Tauricornicaris latizonae, a Chengjiang species interpreted as a radiodont by Zeng et al. (2018b), but more complete material (Fig. 7) indicates that this taxon is more crownward in the Euarthropoda, possessing a sclerotized tergal exoskeleton. The morphology of the four-cusp teeth of Tauricornicaris also differs from that of the GLSs in Amplectobelua and Ramskoeldia, with Tauricornicaris having much larger curved spines relative to the base and a more pronounced successive shortening along the four spines. The same authors also described a single unassigned specimen (NIGPAS 162524) showing five-cusped teeth associated with more typical radiodont structures, including a pair of carapace elements that bear a resemblance to lateral Pelements or possibly the intermediate rod-shaped sclerite in Amplectobelua, tuberculate plates, setal blades and a robust plate with three teeth and prominent nodes (Zeng et al. 2018b, figs 1j, 12). The lack of frontal appendages associated with this assemblage has prevented its definitive identification within Radiodonta, although it was questionably associated with Amplectobelua (Cong et al. 2017). Although it has three pairs of GLSs, these appear to bear only a single row of five teeth, as compared to the multiple rows of four teeth seen in Ramskoeldia and Amplectobelua. These specimens notwithstanding, the presence of three pairs of GLSs in Amplectobelua and Ramskoeldia can be considered as an additional feature to diagnose Amplectobeluidae. As well as this correspondence in number, they are also similar in size relative to other body parts, as well as the numbers, proportions and arrangement of the distal spines, and the presence of the same kind of pointed scales on the distal part of the GLSs. It cannot be excluded that other radiodonts might also bear GLSs, but this complex character does appear to be of systematic value in uniting these genera.

The head carapaces are a set of sclerotized plates in the head region of radiodonts. It is now well appreciated that a central sclerite element on the head is a shared structure across almost all known 
radiodont genera (Daley et al. 2009, 2013b; Cong et al. 2014, 2016, 2017; Ortega-Hernández 2015; Van Roy et al. 2015; Zeng et al. 2018b). A pair of large lateral carapaces (P-elements), that are interpreted as facilitating the collection of food particles, are present in several taxa of the family Hurdiidae, such as two species of Hurdia (Daley et al. 2009, 2013b) and Aegirocassis benmoulai (Van Roy \& Briggs 2011; Van Roy et al. 2015). However, the presence of P-elements is not restricted to Hurdiidae because in Amplectobelua symbrachiata a pair of small P-elements is also present (Cong et al. 2017). Given the presence of similar structures in Ramskoeldia consimilis (Fig. 3A, B, D, E), Pelements appear to be shared at least between Hurdiidae and Amplectobeluidae, between which the size of the P-element relative to other structures in the head is the main difference. This size difference is particularly relevant when considering the affinity of the unassigned radiodont assemblage of Zeng et al. (2018b) discussed above (NIGPAS 162524), which is notable for being one of the only other published radiodont specimens with paired carapace elements (referred to as Aelements by Zeng et al. 2018b) and five-cusped teeth (comparable to GLSs). The carapace elements are relatively small compared to the other body structures, comparable to the condition in Amplectobeluidae. They may be complete P-elements, but the roughly rectangular outline and lack of a prominent beak differ from the morphology of Amplectobelua and Ramskoeldia P-elements. These carapaces are also similar to the rod-shaped sclerite that connects the P-elements in Amplectobelua (Cong et al. 2017), particularly the triangular region between them. Definitive assignment to a genus requires the discovery of a frontal appendage, and in the meantime this specimen is best aligned with Amplectobeluidae. This example shows that the components and morphology of head carapaces have some potential to distinguish families of Radiodonta. Intriguingly, a pair of dorsal cowls has been described overlapping the eye stalk in Lyrarapax, of which the size and position are strikingly similar with P-elements, although detailed morphology, such as the margin and potential ornament, is needed to appraise the homology of these two structures.

Other structures interpreted as radiodont lateral elements were described by Zeng et al. (2018b), but we do not regard these as being radiodont. Specifically, paired R-elements were described as the lateral elements associated with the centrally located Z-elements of Zhenghecaris, although there is no direct evidence for this association in the fossils, but rather it is inferred from the shared presence of a rostral notch complex. The interpretation of Zhenghecaris as a radiodont is based largely on similarity of the carapaces to those of Tauricornicaris, which we have proposed here to be a non-radiodont euarthropod, including the T-, TL-, and TO-elements (Fig. 7). This suggests that Zhenghecaris also should be excluded from Radiodonta and is best considered as more crownward in the euarthropod stem, such as its original interpretation as a bivalved euarthropod (Vannier et al. 2006). This throws into question the radiodont affinity of the potentially associated R-elements. Two other specimens of asymmetrical carapaces were described by Zeng et al. (2018b) as P-elements similar to those of 
Hurdia, but like the R-elements discussed above, these are more similar in detailed morphology (specifically the presence of marginal spines and tubercles, which are absent in radiodonts, including NIGPAS 162524) to the carapaces of Tauricornicaris and Zhenghecaris, and we consider them all to be non-radiodont.

Less well-known in radiodonts are the body flaps. It is now clear that their morphology also varies between different taxa. In most taxa with body flaps preserved, there is a series of parallel transverse lines on the anterior part of the flap, which are normally widely spaced and slightly curved. However, in Anomalocaris canadensis, this kind of transverse line is absent, but replaced by more condensed, thinner lines that resemble wrinkles (Daley \& Edgecombe 2014), whereas in other putative congeners, such as A. saron, the transverse lines on the flaps resemble those of, for example, Peytoia or Amplectobelua (Chen et al. 1994; Hou et al. 1995). In Anomalocaris briggsi, these transverse lines uniquely show an internal structure consisting of a series of striated blocks (Daley et al. 2013a). Lyrarapax also shows variation in flap morphology within the genus, with L. unguispinus (Cong et al. 2014, extended data fig. 3) showing only condensed, thinner lines that resemble wrinkles, whereas in L. trilobus, widely spaced transverse lines are present on the anterior half part of the flaps (Cong et al. 2016). Such variation hampers our ability to summarize characters of flaps to distinguish taxa at the suprageneric level, although it should be acknowledged that the angle between the transverse lines and the proximal-distal axis of the flaps does vary in some taxa. The hurdiid Aegirocassis benmoulai exhibits specializations of the flaps not known in other taxa, such as sclerotized transverse rods composed of minute hollow cones (Van Roy et al. 2015), though comparable styles of preservation might permit the recognition of homologous structures in allied species. Morphology of the body flaps is currently difficult to tap as a source of informative characters above the genus level.

In summary, the feeding structures of radiodonts, including the frontal appendages, the mouth apparatus, the gnathobase-like structures, and at least some head sclerites (P-elements) are all of some taxonomic value, and all contribute characters to the classification of radiodonts. However, the distribution of most characters in all of these feeding structures requires more data to be incorporated into an updated cladistic analysis of Radiodonta, which was previously mainly based on the morphology of the frontal appendages.

\section{Appraisal of other potential members of Amplectobeluidae:}

A previous phylogenetic analysis underpinned the assignment of Lyrarapax to Amplectobeluidae (Cong et al.2014), the single species then known for the genus, uniting it with the two known species of Amplectobelua. This was particularly based on the form and inferred function of the hypertrophied proximal endite (on podomere 4 in Amplectobelua) relative to the distal, strongly articulated part of the frontal appendage. The discovery of Ramskoeldia, which can be more confidently united with 
Amplectobelua, now brings the inferred amplectobeluid affinities of Lyrarapax into question. Firstly, the mouthparts of Lyrarapax are different to those of Amplectobelua and Ramskoeldia in that Lyrarapax lacks the smooth and tuberculate plates known in the latter two genera. Furthermore, there is no sign of GLSs in Lyrarapax in the multiple articulated specimens, despite the reduced postcephalic segments being known. Differences can also be observed in the frontal appendages. As generalized from Amplectobelua and Ramskoeldia, the frontal appendage of Amplectobeluidae consists of a three-podomere shaft and a distal well-articulated region with podomeres 4 and 8 enlarged. In Lyrarapax, the number of podomeres in the shaft is uncertain, and the endite of the most proximal podomere (functionally corresponding to podomere 4 in Amplectobelua and Ramskoeldia) is the only one that is significantly enlarged.

Anomalocaris kunmingensis is the most abundant radiodont in the Guanshan biota, China, the species characterized by one robust proximal endite that bears six pairs of auxiliary spines (Wang et al. 2013). Recent cladistic analyses primarily based on the morphology of the frontal appendage resolved this species as a member of Amplectobeluidae (Vinther et al. 2014; Van Roy et al. 2015). The robust proximal endite is comparable with podomere 4 of Amplectobelua and Ramskoeldia, and some specimens even have an enlarged endite on the podomere corresponding to podomere 8 of the two genera of Amplectobeluidae (Wang et al. 2013, fig. $1 \mathrm{~g}$, h). Recently, it was argued that an isolated tetra-radial oral cone is potentially the mouth part of A. kunmingensis (Zeng et al. 2018a). If this is correct, it conflicts with an affinity with Amplectobeluidae, as the mouthparts of this family do not have a radial arrangement (see above).

\section{Conclusion}

The feeding structures discovered in Ramskoeldia gen. nov. and Amplectobelua (Cong et al. 2017) demonstrate a surprising diversity of feeding strategies in radiodonts, which were traditionally conceived as biting with radial oral cones. It has now become apparent that radiodont feeding ranged from macrophagous predation to filter feeding and sucking (Daley \& Budd 2010; Daley \& Bergström 2012; Van Roy et al. 2015). In the context of the Cambrian explosion, an evolutionary event echoed by ecological diversification, the diversity of feeding strategies in different subgroups indicates that radiodonts were among the first animals to occupy the ecospace in the water column for feeding on various available food resources. It is not a surprise that such a diversification in autecology of radiodonts introduced morphological novelties. The frontal appendages, flaps and mouth apparatus can all be interpreted as modifications of corresponding structures in gilled lobopodians, the putative antecedents of radiodonts (Budd 1998). While GLSs of Amplectobeluidae would be one of the key novelties for feeding in radiodonts, as they are not present in gilled lobopodians, potentially homologous structures are rather widely distributed in the upper-stem and crown groups of 
euarthropods. Given their association with the reduced flaps of the transitional reduced body segments (Cong et al. 2017), the latter having been homologized with the endopods of Euarthropoda (Van Roy et al. 2015), the GLSs may be relevant to understanding how limb components of euarthropods (which are widely adapted for feeding, sensing, swimming, breathing, etc.) were acquired through their stem groups. Thus, it will be of particular interest to determine whether such a novel feeding structure is widespread across Radiodonta or, as presently appears to be the case, is restricted to the members of the Amplectobeluidae.

The presence of GLSs in both Ramskoeldia platyacantha and R. consimilis indicates that these structures are not unique to Amplectobelua symbrachiata, in which they were first documented (Chen et al. 1994; Cong et al. 2017). Together with the similarity of the frontal appendages and the mouth apparatus between Ramskoeldia and Amplectobelua, the detailed similarities in the GLSs provide strong support for Ramskoeldia also being a member of Amplectobeluidae, in which the feeding structures can be clearly distinguished from other well-known radiodonts such as Anomalocaris (Family Anomalocarididae) and Hurdia (Family Hurdiidae). This indicates that the morphology of the feeding structures is not only valid as a source of diagnostic characters at the generic and specific levels, but also at higher taxonomic levels in Radiodonta. This is of particular practical importance as most feeding structures of radiodonts are highly sclerotized and readily preserved, and thus are normally the main part known for most taxa. Such an insight will help to guide the classification of radiodonts as additional species are documented in this increasingly diverse group.

\section{Acknowledgements}

This work was supported by National Science Foundation of China grants 41572015 and U1302232 and Leverhulme Trust Research Project Grant RPG-2015-441. SP was supported by funding from an Oxford-St Catherine's Brade-Natural Motion Scholarship. We thank referees Javier Ortega-Hernández and Peter Van Roy for their constructive feedback.

\section{Literature cited}

Bergström, J. 1986. Opabinia and Anomalocaris, unique Cambrian 'arthropods'. Lethaia, 19, 214246.

Bergström, J. 1987. The Cambrian Opabinia and Anomalocaris. Lethaia, 20, 187- 188.

Briggs, D. E. G. 1979. Anomalocaris, the largest known Cambrian arthropod. Palaeontology, 22, $631-663$. 
Briggs, D. E. G. and Whittington, H. B. 1987. The affinities of the Cambrian animals Anomalocaris and Opabinia. Lethaia, 20, 185- 186.

Budd, G. E. 1998. Stem group arthropods from the Lower Cambrian Sirius Passet fauna of North Greenland. 125- 138. In R. A. Fortey and R. H. Thomas (eds). Arthropod relationships, Systematics Association Special Volume, 55, Chapman \& Hall.

Chen, J., Ramsköld, L. and Zhou, G. 1994. Evidence for monophyly and arthropod affinity of Cambrian giant predators. Science, 264, 1304- 1308.

Collins, D. 1996. The "evolution" of Anomalocaris and its classification in the arthropod class Dinocarida (nov.) and order Radiodonta (nov.) Journal of Paleontology, 70, 280- 293.

Cong, P., Ma, X., Hou, X., Edgecombe, G. D. and Strausfeld, N. J. 2014. Brain structure resolves the segmental affinity of anomalocaridid appendages. Nature, 513, 538- 542.

Cong, P., Daley, A. C., Edgecombe, G. D. and Hou, X. 2016. Morphology of the radiodontan Lyrarapax from the early Cambrian Chengjiang biota. Journal of Paleontology, 90, 663-671.

Cong, P., Daley, A. C., Edgecombe, G. D. and Hou, X. 2017. The functional head of the Cambrian radiodontan (stem-group Euarthropoda) Amplectobelua symbrachiata. BMC Evolutionary Biology, 17, 208.

Daley, A. C. and Bergström, J. 2012. The oral cone of Anomalocaris is not a classic "peytoia". Naturwissenschaften, 99, 501-504.

Daley, A. C. and Budd, G. E. 2010. New anomalocaridid appendages from the Burgess Shale, Canada. Palaeontology, 53, 721- 738.

Daley, A. C. and Edgecombe, G. D. 2014. Morphology of Anomalocaris canadensis from the Burgess Shale. Journal of Paleontology, 88, 68-91.

Daley, A. C. and Peel, J. S. 2010. A possible anomalocaridid from the Cambrian Sirius Passet Lagerstätte, North Greenland. Journal of Paleontology, 84, 352- 355.

Daley, A. C., Budd, G. E., Caron, J.-B., Edgecombe, G. D. and Collins, D. 2009. The Burgess Shale anomalocaridid Hurdia and its significance for early euarthropod evolution. Science, 323, $1597-1600$. 
Daley, A. C., Paterson, J. R., Edgecombe, G. D., García-Bellido, D. C. and Jago, J. B. 2013a. New anatomical information on Anomalocaris from the Cambrian Emu Bay Shale of South Australia and a reassessment of its inferred predatory habits. Palaeontology, 56, 971-990.

Daley, A. C., Budd, G. E. and Caron, J.-B. 2013b. Morphology and systematics of the anomalocarid arthropod Hurdia from the Middle Cambrian of British Columbia and Utah. Journal of Systematic Palaeontology, 11, 743- 787.

Haug, J. T., Waloszek, D., Maas, A., Liu, Y. and Haug, C. 2012. Functional morphology, ontogeny and evolution of mantis shrimp-like predators in the Cambrian. Palaeontology, 55, 369-399.

Hou, X. and Bergström, J. 1991. The arthropods of the Lower Cambrian Chengjiang fauna, with relationships and evolutionary significance. 179- 187. In A. M. Simonetta and S. Conway Morris (eds). The early evolution of Metazoa and the significance of problematic taxa, Cambridge University Press.

Hou, X., Bergström, J. and Ahlberg, P. 1995. Anomalocaris and other large animals in the lower Cambrian Chengjiang fauna of southwest China. GFF, 117, 163- 183.

Hou, X., Siveter, D. J., Siveter, D. J., Aldridge, R., Cong, P., Gabbott, S. E., Ma, X., Purnell, M. A. and Williams, M. 2017. The Cambrian fossils of Chengjiang, China: the flowering of early animal life. 2nd edn. Wiley, $316 \mathrm{pp}$.

Kühl, G., Briggs, D. E. G. and Rust, J. 2009. A great-appendage arthropod with a radial mouth from the Lower Devonian Hunsrück Slate, Germany. Science, 323, 771- 773.

Lankester, R. E. 1904. The structure and classification of the Arthropoda. The Quarterly Journal of Microscopical Science, 47, 523- 582.

Legg, D. A., Sutton, M. D. and Edgecombe, G. D. 2013. Arthropod fossil data increase congruence of morphological and molecular phylogenies. Nature Communications, 4, 2485.

Luo, H., Hu, S., Chen, L., Zhang, S. and Tao, Y. 1999. Early Cambrian Chengjiang fauna from Kunming Region, China. Yunnan Science \& Technology Press, Kunming, 129 pp, 32 pls. [in Chinese, English summary]

Nedin, C. 1995. The Emu Bay Shale, a Lower Cambrian fossil Lagerstätten, Kangaroo Island, South Australia. Memoirs of the Association of Australasian Palaeontologists, 18, 31- 40. 
Ortega-Hernández, J. 2015. Homology of head sclerites in Burgess Shale euarthropods. Current Biology, 25, 1625- 1631.

Ortega-Hernández, J. 2016. Making sense of 'lower' and 'upper' stem-group Euarthropoda, with comments on the strict use of the name Euarthropoda von Siebold, 1848. Biological Reviews, 91, 255- 273.

Ramsköld, L. 1995. From characters to clades: interpreting lobopodians and anomalocaridids. In J. Chen, G. Edgecombe and L. Ramsköld (eds). Programme and abstracts of the International Cambrian explosion symposium. Nanjing Institute of Geology and Palaeontology, CAS, Nanjing, 22, 48 pp.

Raymond, P. E. 1935. Leanchoilia and other mid-Cambrian Arthropoda. Bulletin of the Museum of Comparative Zoology at Harvard College, 76, 205- 230.

Vannier, J., Cheng, J., Huang, D., Charbonnier, S. and Wang, X. 2006. The Early Cambrian origin of thylacocephalan arthropods. Acta Palaeontologica Polonica, 51, 201-214.

Van Roy, P. and Briggs, D. E. G. 2011. A giant Ordovician anomalocaridid. Nature, 473, 510- 513.

Van Roy, P., Daley, A. C. and Briggs, D. E. G. 2015. Anomalocaridid trunk limb homology revealed by a giant filter-feeder with paired flaps. Nature, $522,77-80$.

Vinther, J., Stein, M., Longrich, N. R. and Harper, D. A. T. 2014. A suspension-feeding anomalocarid from the Early Cambrian. Nature, 507, 496- 499.

Wang, Y., Huang, D. and Hu, S. 2013. New anomalocaridid frontal appendages from the Guanshan biota, eastern Yunnan. Chinese Science Bulletin, 58, 3937- 3942.

Whittington, H. B. and Briggs, D. E. G. 1985. The largest Cambrian animal, Anomalocaris, Burgess Shale, British Columbia. Philosophical Transactions of the Royal Society B, 309, 569-609.

Zeng, H., Zhao, F., Yin, Z. and Zhu, M. 2018a. A new radiodontan oral cone with a unique combination of anatomical features from the early Cambrian Guanshan Lagerstätte, eastern Yunnan, South China. Journal of Paleontology, 92, 40- 48.

Zeng, H., Zhao, F., Yin, Z. and Zhu, M. 2018b. Morphology of diverse radiodontan head sclerites from the early Cambrian Chengjiang Lagerstätte, south-west China. Journal of Systematic 
Palaeontology, 16, 1- 37 .

\section{Figure captions:}

Figure 1. Ramskoeldia platyacantha gen. et sp. nov. from the Chengjiang biota. A, holotype, YKLP 13325, showing frontal appendages, GLSs, mouth apparatus and flaps. B-C, paratype, frontal appendage, YKLP 13337, showing the ventral spines. D, interpretative drawing of the holotype. E, close-up of a pair of GLSs and mouth plates in the holotype (boxed in A). F, close-up of GLSs and row of small ventrolateral spines in high relief in the holotype (boxed in A), filled arrows indicate small endites preserved in high relief; open arrow indicates a socket. G-H, YKLP 13331, a small frontal appendage. Abbreviations: ce, central element of head; ds, dorsal (outer) spine of frontal appendage; en, endite on ventral (inner) side of podomeres; fl, flap; gls, gnathobase-like structures (GLS); pd, podomere; rf, reduced flaps; sc, scale-like ornamentation on stem of GLS; se, small endites at lateral side of podomeres; sp, smooth plates; tp, tuberculate plates; ts, terminal spine on termination of most distal podomere. Scale bars represent: $1 \mathrm{~cm}(\mathrm{~A}, \mathrm{D}) ; 2 \mathrm{~cm}(\mathrm{~B}, \mathrm{C}) ; 3 \mathrm{~mm}(\mathrm{E}) ; 5 \mathrm{~mm}$ $(\mathrm{F}-\mathrm{H})$.

Figure 2. Frontal appendages of Ramskoeldia platyacantha gen. et sp. nov. from the Chengiiang biota. A-B, part and counterpart of CJHMD 00001. C-D, part and counterpart of CJHMD 00002. EF, interpretative drawing of A and B. G-H, interpretative drawing of C and D. Abbreviations: ds, dorsal (outer) spine of frontal appendage; en, endite on ventral (inner) side of podomeres; pd, podomere; se, small endites at lateral side of podomeres; ts, terminal spine on termination of most distal podomere. All scale bars represent $5 \mathrm{~mm}$.

Figure 3. Holotype (YKLP 13315) of Ramskoeldia consimilis gen. et sp. nov. from the Chengjiang biota. A, part of the holotype. B, interpretative drawing of A. C, close-up of mouth region boxed in A, note the opposite directions of the distal spines of GLSs (see labelling in B). D, counterpart of the holotype. E, interpretative drawing of C. Abbreviations: ds, dorsal (outer) spine of frontal appendage; en, endite on ventral (inner) side of podomeres; fl, flap; gls, gnathobase-like structures (GLS); pe, Pelement; pd, podomere; rf, reduced flaps; sp, smooth plates; tp, tuberculate plates. Scale bars represent: $5 \mathrm{~mm}(\mathrm{~A}, \mathrm{~B}, \mathrm{D}, \mathrm{E}) ; 2 \mathrm{~mm}(\mathrm{C})$.

Figure 4. Frontal appendages of Ramskoeldia consimilis gen. et sp. nov. from the Chengjiang biota. A-B, part and counterpart of YKLP 13327. C, close-up of the small endites, boxed in B, arrows 
indicating the small endites. D, YKLP 13329. E-F, interpretative drawings of A and B. G, interpretative drawing of D. Abbreviations: ds, dorsal (outer) spine of frontal appendage; en, endite on ventral (inner) side of podomeres; pd, podomere; se, small endites at lateral side of podomeres; ts, terminal spine on termination of most distal podomere. Scale bars represent: $2 \mathrm{~mm}(\mathrm{~A}, \mathrm{~B}, \mathrm{D}-\mathrm{G})$; $1 \mathrm{~mm}(\mathrm{C})$.

Figure 5. Comparison of the frontal appendage between Ramskoeldia consimilis gen. et sp. nov. and Anomalocaris saron. A-B, part and counterpart of YKLP 13328, frontal appendage of $R$. consimilis. C, YKLP 13886a, frontal appendage of A. saron. D-E, interpretative drawings of A and B. F, interpretative drawing of C. Abbreviations: ds, dorsal (outer) spine of frontal appendage; en, endite on ventral (inner) side of podomeres; pd, podomere; ts, terminal spine on termination of most distal podomere. Scale bars represent $2 \mathrm{~mm}(\mathrm{~A}, \mathrm{~B}, \mathrm{D}, \mathrm{E}) ; 5 \mathrm{~mm}(\mathrm{C}, \mathrm{F})$.

Figure 6. Oral cones and associated gnathobase-like structures of Radiodonta. A, Amplectobeluidae, note that the arrangement of plates in the central region is conjectural. B, Lyrarapax. C, Anomalocarididae. D, Guanshan oral cone. E, Hurdia. F, Peytoia. A adapted from Cong et al. (2017); C, E, F adapted from Daley \& Bergström 2012; D adapted from Zeng et al. (2018b).

Figure 7. Articulated specimen of Tauricornicaris latizonae Zeng et al., 2018b, previously interpreted as a hurdiid. A, YKLP 13339, showing articulated tergites, black solid arrows indicating the increasing length of the posterior-lateral projection. B, close-up of a tergite (boxed in A), showing the ornament; hollow white arrows show regularly large spines on the lateral margin of the tergite. Scale bars represent: $2 \mathrm{~cm}(\mathrm{~A}) ; 5 \mathrm{~mm}(\mathrm{~B})$. 


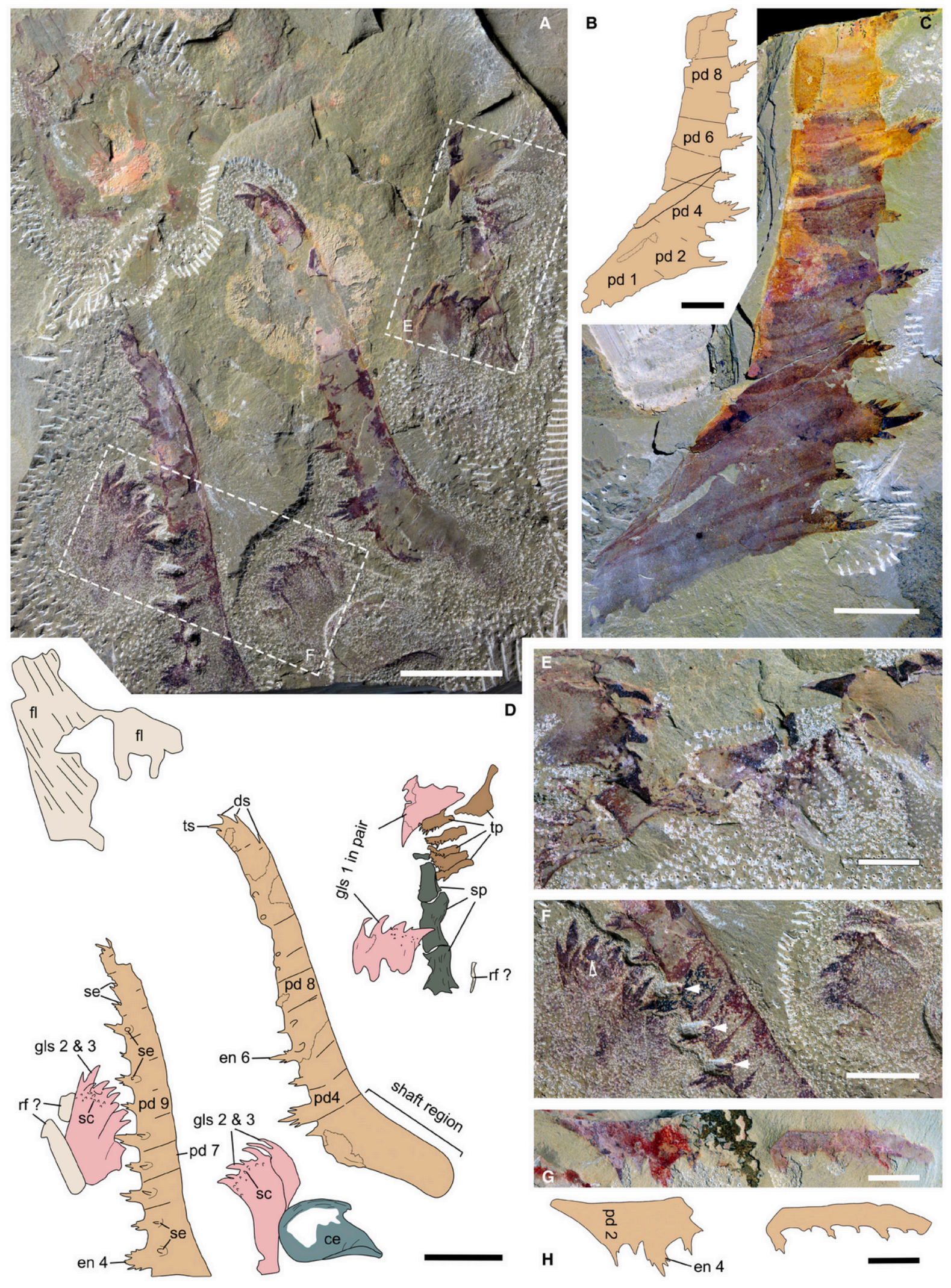

Figure 1 

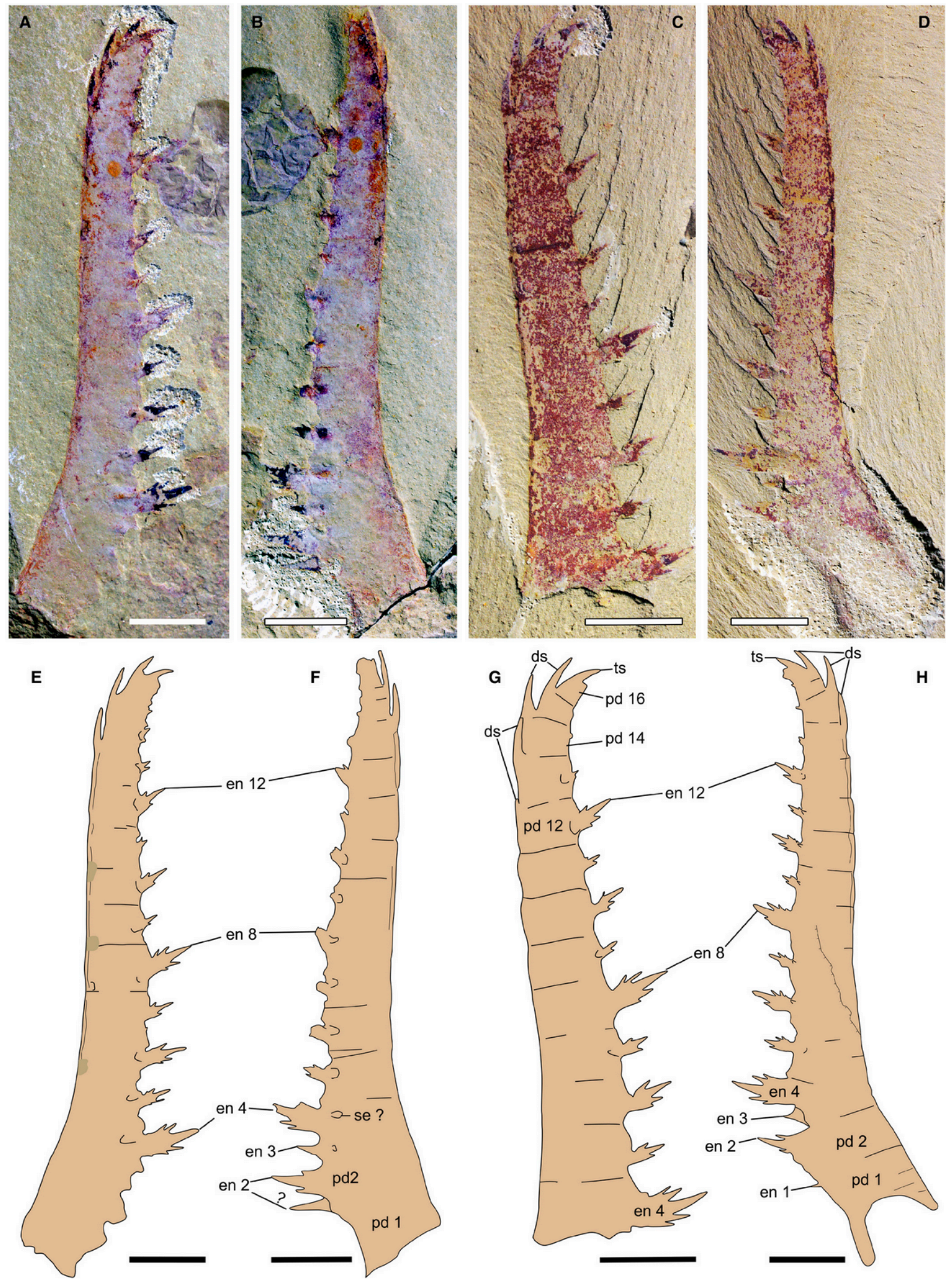

Figure 2 

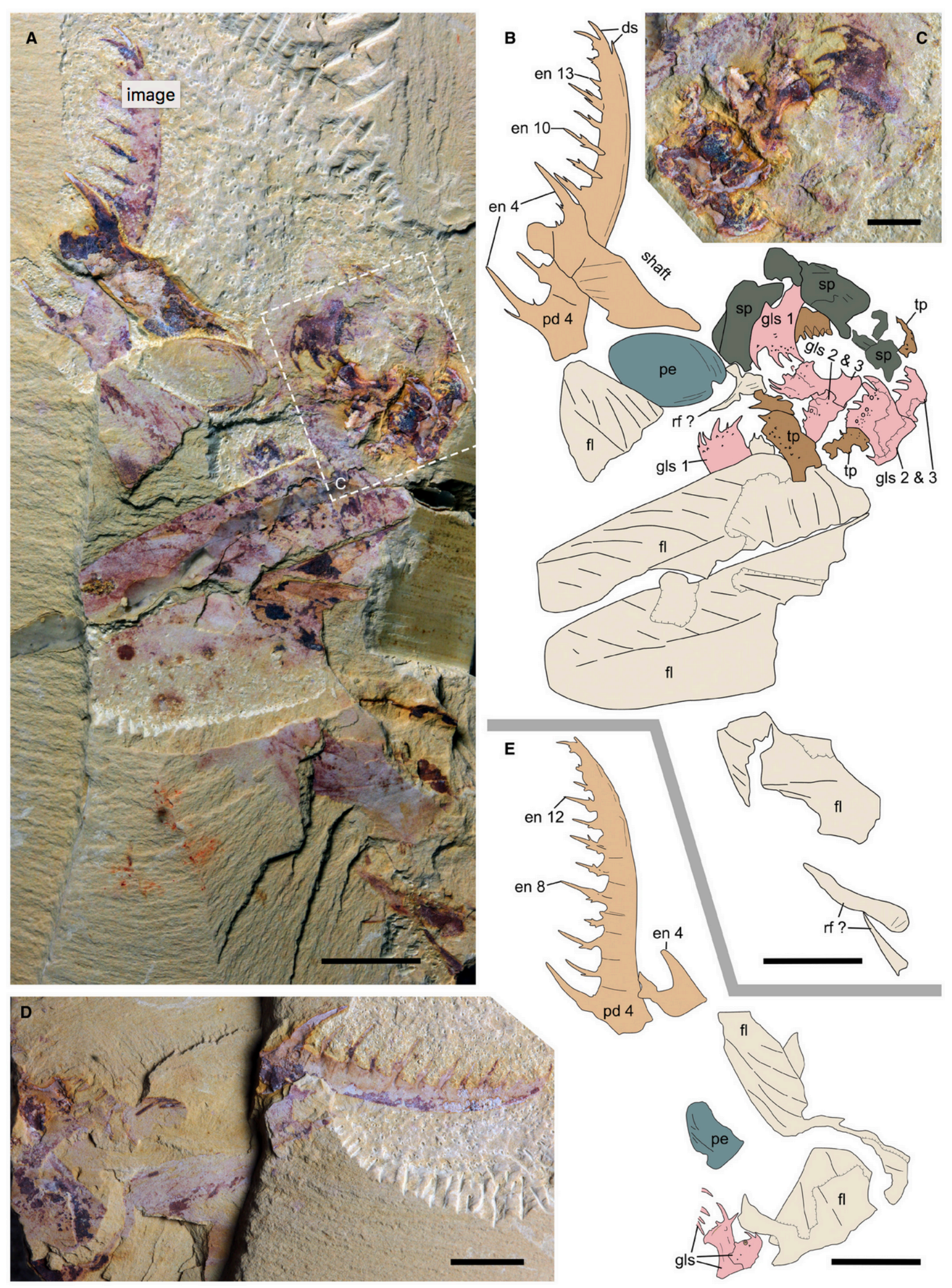

Figure 3 

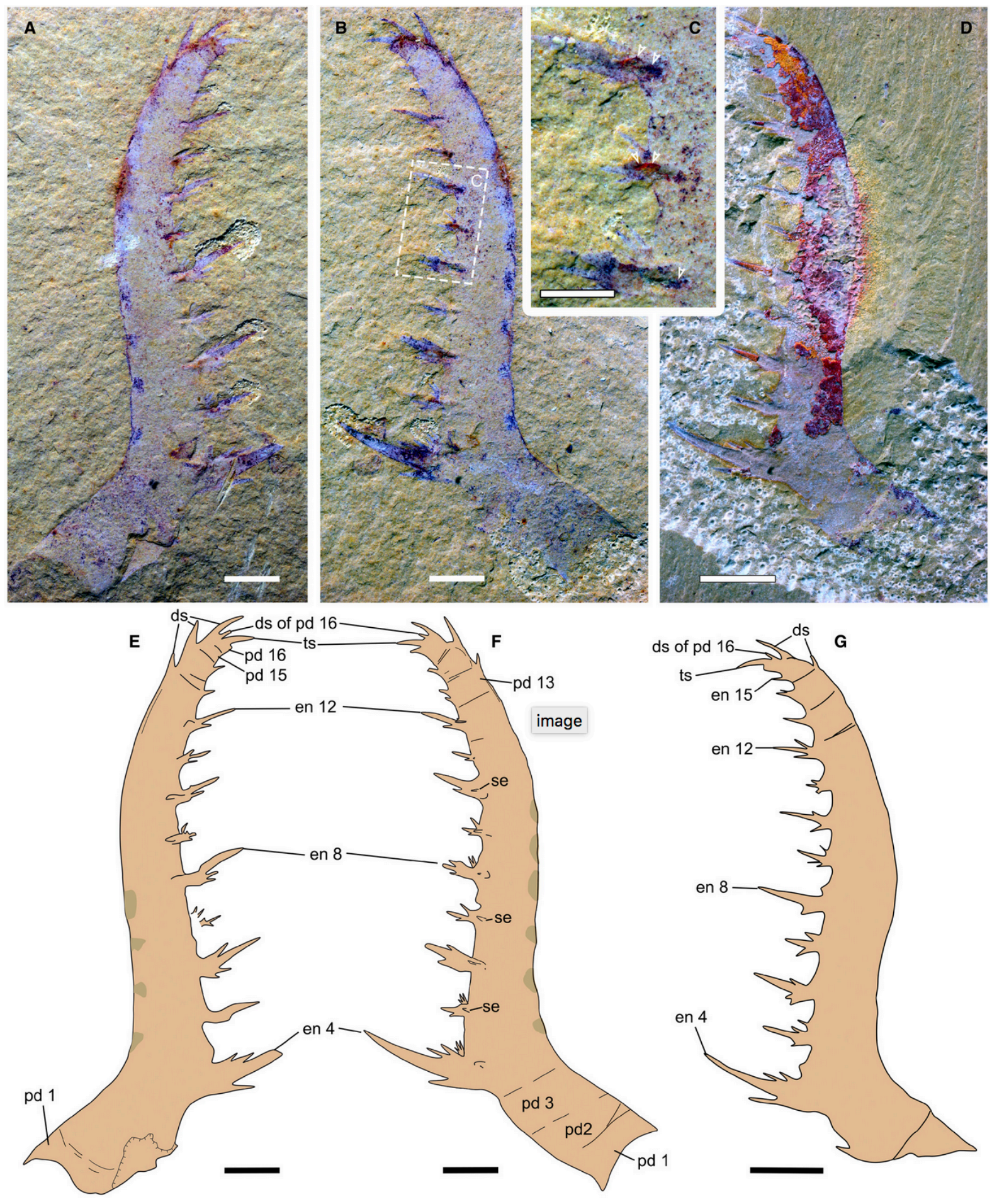

Figure 4 

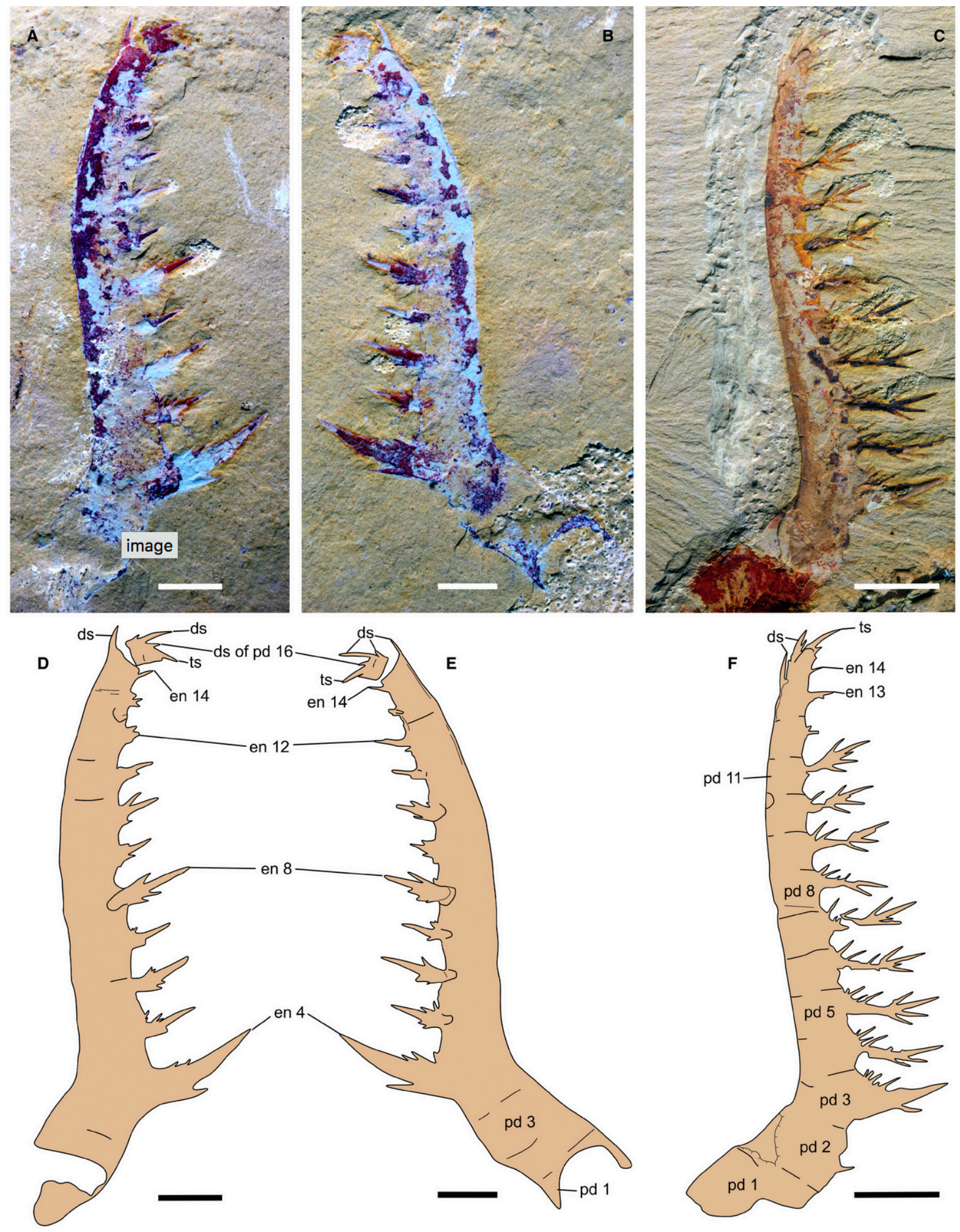

Figure 5 

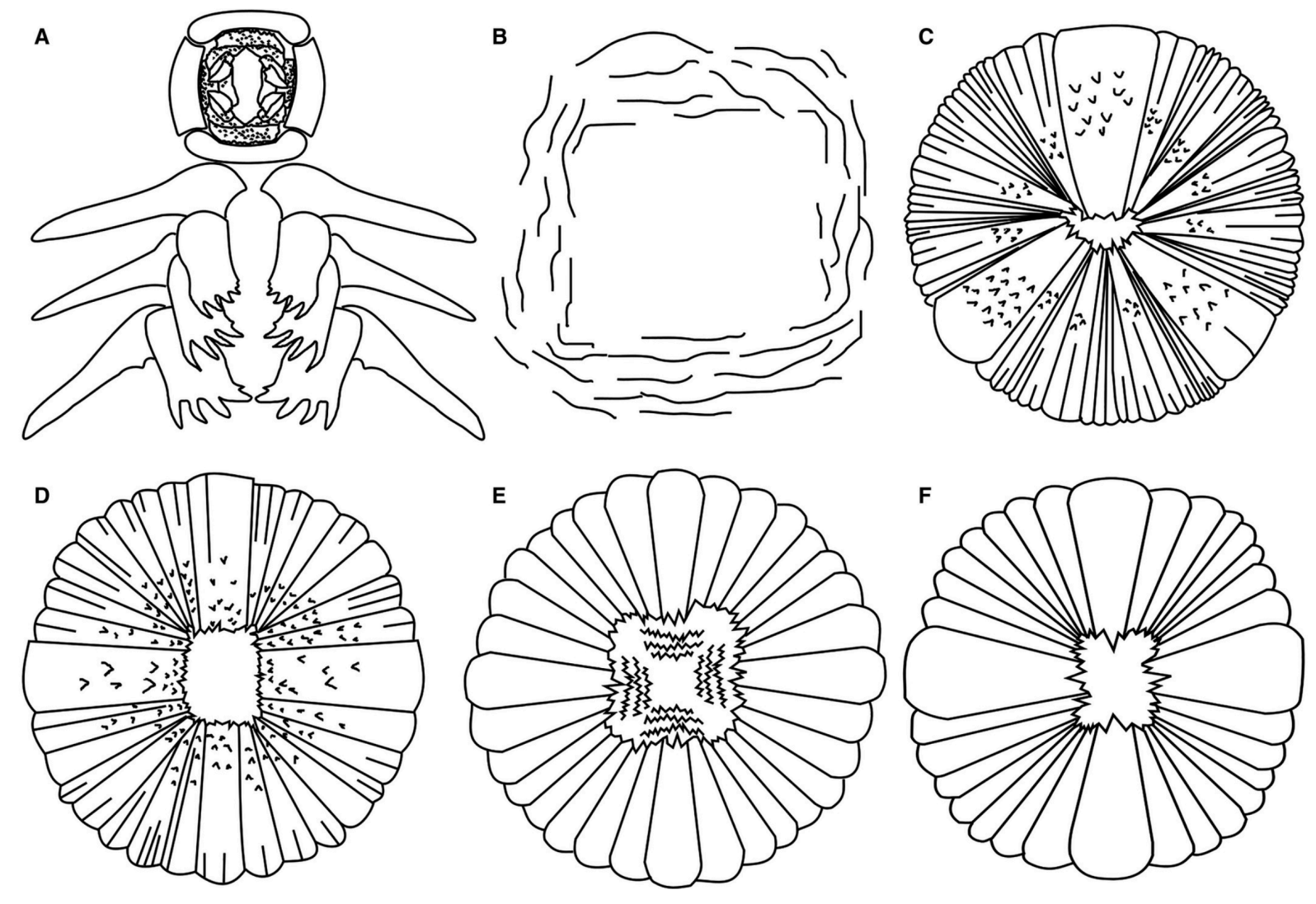

Figure 6 


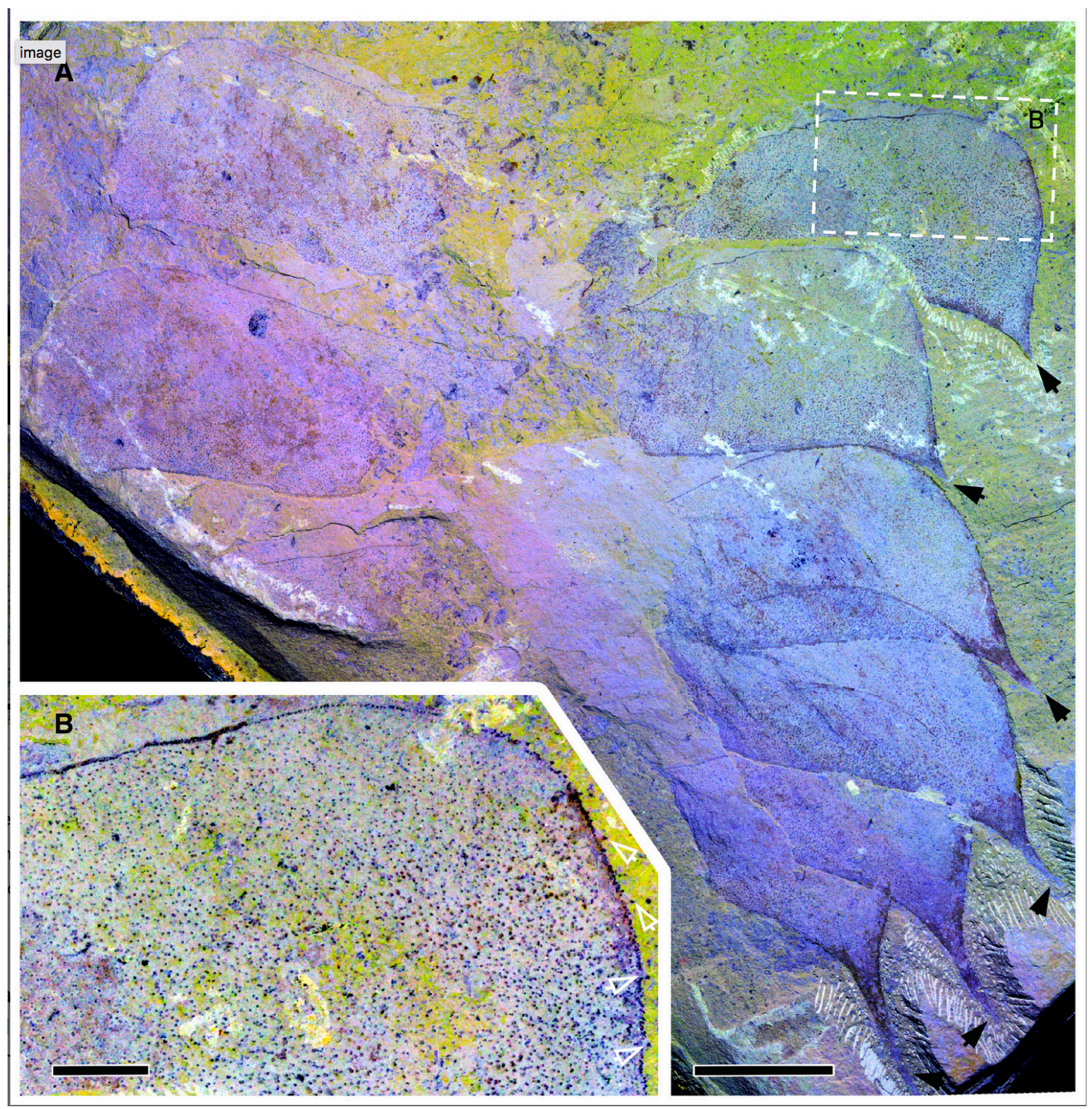

Figure 7 